\title{
New Operational Types of the Transportation Industry and the Countermeasures for Regulating them
}

\author{
Yan-xia LI', a , and Zhi-hua DING ${ }^{2}$ b $^{*}$ \\ ${ }^{1,2}$ China Academy of Transportation Sciences, Beijing, China \\ a2211974401@qq.com, bzhding74@sina.com \\ ${ }^{*}$ Corresponding author
}

\begin{abstract}
Keywords: Transportation industry, New operational types, Regulation.
Abstract. At present, it is urgent to study how to regulate new operational types of the transportation industry such as "Internet+Transportation", autonomous driving and UAVs well in China, with the application of new technologies such as "Internet+", artificial intelligence and big data. The development of such types in the country has been described. After that, legal obstacles affecting new operational types of the transportation industry are discovered and analyzed. For them, the countermeasures are put forward.
\end{abstract}

\section{Introduction}

In recent years, with the application of new technologies such as "Internet+", artificial intelligence and big data, new operational types of the transportation industry such as "Internet+Transportation", autonomous driving and UAVs have developed rapidly. Existing laws and regulations concerning the transportation industry have been formulated for traditional operations types in the industry. New operational types in the industry are facing some new legal problems. How to resolve such problems and regulate new operational types in the industry well is becoming an important topic.

\section{Emerging New Operational Types of the Transportation Industry in China}

Internet + Transportation. "Internet+Transportation", supported by new technologies of Internet or Mobile Internet, and deeply integrating the innovation results of Internet with the transportation industry, has promoted technological progress, efficiency improvement and organizational change, and formed new and more extensive operational types of transportation taking Internet as infrastructure and innovation elements. This is mainly reflected in the following respects. Firstly, "Internet + Passenger transport" continues to emerge. The on-line ticketing system for road passenger transport is operating in the market; the customized service for "point-to-point" road passenger transport is spreading rapidly; the passenger transport of shuttle bus and charter bus has an obvious trend to integration; Internet intercity passenger transport becomes a new operation condition attracting the attention of industry and society. Secondly, "Internet+Freight" grows quickly. Transportation resources, such as scattered transport service providers, freight sources, and station yards, are combined through network platform and mobile internet technology, to provide one-stop transport service and a vehicle-free transport logistics mode taking the whole-course responsibility and risks, and to realize the innovative fusion of new mode and new operational condition with traditional freight, E-commerce and multimode transport, and to push forward the reasonable distribution of on-line resource and the efficient running of off-line logistics, thereby greatly facilitating the industrial transformation and upgrading and the cost reduction and efficiency improvement of logistics. Thirdly, "Internet+Taxi" is developing in an orderly manner. The basic norms on the development of online car-hailing business are initially established, which contains the disorderly development and vicious competition of the business as a whole. Fourthly, "Internet+Services" is following closely. There are two main types of service mode. One is the light mode that only serves as a platform. It attracts consumers to make an order through online channel, and directs such online customers to offline stores. Another mode serves as both platform and offline 
stores. The enterprises in such mode generally have their own physical stores, and are able to provide comprehensive and timely service, or even door-to-door service. At present, leading companies such as Alibaba, JD.com and Gome have set up their respective working platform for online development of auto repair market and started to enter the sector of auto repair. There are about a hundred of e-commerce service platforms of other types.

Auto-Driving Vehicle. From various aspects, auto-driving technology is expected to have many application scenarios in the fields of road passenger transport, taxi industry, parking management and highways. In respect of the impact of automatic driving technology on transportation, the information collected and sorted out shows that the sheer automatic driving technology (unmanned vehicle) is far away from actual application; automatic driving technology, as a systematic integration technology, isn't only related with the technical performance of the vehicle itself, but also involved with facilities and equipment, marking lines, operating environment and others factors. At present, automatic driving technology is still in the stages of investigation, research and information acquisition. However, more attention shall be paid to the following three aspects, that is, the synergy ability between vehicles and roads, the improvement of automatic driving to active safety of operating vehicles, and the gradual introduction of auxiliary driving system to existing standard and regulation system.

UAVs. Unmanned Aerial Vehicle (UAV), commonly known as drone, is a kind of unmanned airplane which is subject to radio remote control or is controlled mainly by its own program. It is expected that in the coming period, with the rapid development and maturity of unpiloted aircraft technology, the prospect of its application in the transportation field will be broad. Firstly, it can be used for traffic emergency rescue. For example, after the occurrence of geological and meteorological disasters such as earthquakes, mudslides and snowstorms, and under the emergency situations of road blockage and power \& communication interruption, UAVs can be used to realize aerial photographing and detection over the conditions and damaged roads in disaster-hit and epicenter areas, and to direct rescue operations. It can also be used to spray snow melting agent on snow-covered roads during snow and ice disasters, and to quickly melt and clear the snow and ice collected on road. Secondly, it can be used for logistics and distribution. For example, UAVs can be used to realize express delivery to remote mountainous areas, inaccessible areas, and to realize a high-end customized distribution in urban areas. Thirdly, it can be used in the fields of maritime mapping, beacon navigation, maritime communication, etc., so as to exert the technical advantages of flying near-ground, being quick and efficient, flexible, and free from surface water conditions. Therefore, although UAVs are not widely used in the transportation industry, it will be expected to have a period of rapid development in the next 3-5 years.

Unmanned Ships. Unmanned ship is a general term of a class of ships that are controlled directly by an autonomous navigation system or a shore-based steering center to maintain normal navigation and operations without a crew member. Compared with traditional ships, unmanned ships have advantages in terms of safety, efficiency, cost and environmental protection. Unmanned ships will completely change ship design, global marine cargo transportation operation and the development model and competitive landscape of related industries. Unmanned ship will, in design, break through the limitations of traditional manned ship design and satisfy, to the maximum extent, the actual needs of cargo transportation. The application of a large number of sensors and new technologies and new equipment in relation to artificial intelligence will pose a profound impact on and bring a fundamental change to the existing design concept of hull and propulsion system and the shipbuilding processes. In addition, the changes of control mode, operation mode and management mode of unmanned vessels will bring a major change to the production and operation mode, industrial conditions and business model of shipping companies, port companies and shipping service enterprises, and will lead to a centralized operation and management on distributed fleet of unmanned ships in the world, and generate a larger-scale marine freight online service market, and other various new industrial formats and business modes. At present, the international conventions and domestic laws and regulations concerning the supervision of unmanned ships are not sound, and there are no clear regulations on the 
navigation safety, collision avoidance rules, legal liability and insurance in respect of unmanned ships, which will pose a major change and influence on current maritime supervision. Unmanned ships are controlled, operated and maintained in a centralized manner by shore-based operators, in reliance on remote intelligence control and unmanned auto driving technology. The demand for the number of crew members will greatly reduce, and the training mode and knowledge structure of maritime talents will undergo a fundamental change. The demand for versatile talents who master ship control technology, operation and maintenance technology and artificial intelligence technology will continue to increase. This will further have a far-reaching effect on the training of maritime talents.

\section{Legal Obstacles Faced by and Legislative Demands of New Operational Types}

Different from traditional transportation and manned vehicles and aircrafts, ships, Internet+transportation and unmanned vehicles, aircrafts, ships and other new operational types rely on new Internet technologies to create a new mode of operation. Current laws and regulations are difficult to adjust the new complex relationship well, and on-going practice also calls for new legislations. For this, it is necessary to sort out the key legal obstacles to further development of new operational types of the transportation industry and key issues to be solved through legislations.

Internet+Transportation. In respect of Internet+passenger transport, existing legal questions are stated as the following. Firstly, road passenger transport service by use of network platform faces institutional bottlenecks in respect of outside-station passenger pickup, independent selection of operation lines, station loading at different place, fare determination and so on. Secondly, there are no laws and regulations governing customized service of road passenger transport and other new service forms. For example, the country has clearly propose to give full play to the role of mobile Internet and other information technologies, and to encourage and standardize the development of flexible, fast, and small-volume customized service of road passenger transport, but there are no definite provisions therefor in existing laws and regulations.

In respect of Internet+freight, the nature and positioning of car-free carrier is not clear. The industry and the academic community have not reach a consensus on the nature, legal status, role and management of car-free carriers, and whether they have to be licensed. How to regulate car-free carriage is not clear and needs to be further explored. There is also no platform management system and norms. Online platform involves information registration, release, matching, transaction, transportation supervision and other links, but there are no specific provisions on the relationship of rights and obligations between online platform and consignor or actual carrier, nor supervision rules for online platform.

In respect of Internet+taxi, the regulations on online taxi-hailing service have a lower level of effect, and are weak in force. At present, the national and local authorities have issued some regulations on online taxi-hailing service, mainly in the form of normative documents. Some social vehicles, soliciting guests through online platforms and Wechat public accounts, and operating illegally, are out of supervision and are a huge safety hazard. This will affect the long-term healthy development of online taxi-hailing service. There are also many problems in the enforcement of existing regulations. For example, the on-line vehicles and drivers for online taxi-hailing service are inconsistent with the vehicles and drivers providing offline service. The data transmission from platform company of online taxi-hailing service to government regulatory platform has a serious problem in integrity, accuracy and real-time.

In respect of Internet+maintenance, the relevant laws, regulations and standards are lagging behind. At present, the service specifications of auto repair e-commerce enterprises lag behind, the management laws and regulations are not sound, and the industry lacks supervision means. Especially, in the respects of e-commerce main body admittance, trading behavior and on-site repair, the lack of laws and regulations coexists with the breach of laws and regulations. There are some difficulties in data interaction between E-commerce platform and management department. E-commerce platforms and industrial information management platforms haven't formed an effective interconnection 
mechanism and the information sharing and exchange channels are not smooth. The protection of consumer rights is defective. Some e-commerce platforms are only responsible for attracting customers online, and offline services are done by contracting physical stores. In case of service dispute, it is not clear whether the related liabilities are to be borne by e-commerce platform or offline store, and how consumer rights can be protected.

Auto-Driving Vehicle. The current traffic regulations take manual driving as a precondition, and the institutional design at large cannot be applied to automatic driving. According to the Law of the People's Republic of China on Road Traffic Safety (hereinafter referred to as the "Road Traffic Safety Law") and the Regulations on the Implementation of Road Traffic Safety Law, a driver of motor vehicle shall obtain a motor vehicle driving license according to law, and any person meeting the driving license conditions stipulated by the Ministry of Public Security of the State Council shall apply for a driving license for motor vehicle. This actually prohibits the automatic vehicle driving. The partial structure and function of automatic driving vehicles (such as the front camera and automatic steering) don't meet the mandatory standards for traditional non-intelligent or non-networking vehicles. Therefore, the driving of such non-compliant vehicles in structure or function actually violates the provisions of Article 21 of Road Traffic Safety Law, and the driver must bear the corresponding legal responsibility therefor. The Regulations on the Implementation of the Road Traffic Safety Law provides that "motor vehicles running on the highway are not allowed to be tested", which prohibits the driving of self-driving cars on expressways for purpose of development, testing and verification. In addition, the development of unmanned vehicles also depends on the open and authorized applications of high-precision positioning, digital map and other technologies. At present, there are still some regulatory or institutional obstacles.

UAVs. At present, the development of drones in China also lacks a legal basis. Firstly, UAV production has no industrial admittance threshold, and the duties of relevant regulatory authorities are not clear. Secondly, the use of UAVs is unregulated, which has caused some prominent problems, for example, hampering the normal flight of military and civilian manned airplanes, accidental dropping and causing human injuries, making aerial photographs to infringe citizens' privacy, illegal mapping for divulgence of national secrets, and deliberate attacks on vital facilities. These problems have, to a great extent, affected and interfered with healthy development of the manufacture and use of unmanned aircrafts.

Unmanned Ships. Many current and important legal systems are not, fully or partially, applicable to manned ships. Some major legal obstacles are stated as the following. According to the United Nations Convention on the Law of the Sea, only those vessels that meet the conditions stipulated by the laws of a country, acquire its nationality and have the right to fly its national flag can enjoy the right to free navigation on the high seas or exclusive economic zones and to innocent passage in territorial sea. Marine Traffic Safety Law, Ship Registration Regulations and the Regulations on the Inspection of Ships and Offshore Installations also make corresponding provisions on the conditions for ships' acquisition of nationality. In principle, these provisions should also be applicable to unmanned ships. According to the Regulations on the Inspection of Ships and Offshore Installations, unmanned ships of Chinese nationality in the $R \& D$ and experimental phase must apply for construction inspections during the construction phase and must be inspected periodically during operation. However, there is a blank in the current regulations on whether the design of the unmanned ship should pass the inspection by the inspection agency and whether it is necessary to apply for classification inspection after the completion of the construction. Since unmanned ships has no crew members, and their navigation is controlled only by onshore operators, accordingly, the provisions of Maritime Traffic Safety Law and the Minimum Safe Manning Rules for Ships in respect of ship manning cannot be directly applied to unmanned ships. According to the current regulations on ship manning, it is illegal for unmanned ships to navigate without crew members. 


\section{Countermeasures for Strengthening the Regulation of New Operational Types}

Considering the fact that the legislations are basically blank for the above-mentioned new operational types of the transportation field, and a comprehensive research and planning concerning the legislation for new operational types is required. In terms of legislative technology, it is possible to make separate laws for a specific field, or to modify the existing relevant laws and regulations, thereby reflecting the promotion of development of such new operational type. Therefore, according to the current and future needs for development of new operational types of the transportation field, the following countermeasures are put forward.

Internet+Transportation. Internet+transportation has developed rapidly in recent years and has an increasing influence on people's traveling. It is recommended to speed up the legislative process therefor. In respect of the provisions on passenger transport, freight transport, taxis, maintenance and so on, it is suggested to amend the Road Transport Regulations or enact the Road Transport Law as a solution. Firstly, push forward the reform of the licensing system on a continuous basis. It is required to give full play to the business autonomy of enterprises in the market, and to return the operational matters of site, shift, time and vehicle model to the market, and to gradually work out the problem of excessive licensing and management. Secondly, push forward the customization of passenger services. The relevant requirements for customized services for road passenger transport shall be further clarified and refined. The enterprises shall be encouraged to determine the stops, daily shifts, vehicle models and quantity according to passengers' needs, and to flexibly choose passengers' loading points under the precondition that traffic safety regulations are not breached, and safety and order can be guaranteed. Thirdly, make clear whether the passenger vehicles for online taxi-hailing service can engage in intercity passenger transport services. It is forbidden for online taxi-hailing service platforms or pooling cars to engage in road passenger transportation operation openly or in disguised form. Fourthly, make the management of car-free carriers subject to road transport laws and regulations. It is necessary to add the legal provisions for "regulating the operation and development of car-free carriers", thereby determining the legal status of car-free carriers at the legislative level, and building a sound institutional environment for the development of car-free carriers. Fifthly, make the taxi management subject to road transport laws and regulations. Further measures will be taken to promote the standard management of online taxi-hailing service, and to promote the fair competition and fusion development of online taxi-hailing service and cruise taxi service.

Auto-Driving Vehicle. The laws on automatic driving vehicles should be made in the principle of "amending old provisions and establishing new ones". Firstly, we must promptly revise the relevant norms that are not suitable for the development of smart cars. More specifically, we should revise the relevant provisions of Road Traffic Safety Law and its Implementation Regulations, Highway Law, Highway Safety Protection Regulations and its Regulations and so on, to eliminate legal obstacles to smart car testing and getting on road; under the precondition of national security, we should revise the relevant provisions of the "Surveying and Mapping Law" and "Map Management Regulations" and other laws and regulations will be revised to create conditions for high-precision map mapping for vehicle use. Secondly, we should adhere to the national unified legislation, do a good job in top-level design, and avoid departmental legislative conflicts. It is also advisable to clearly define the management authority of the component departments of the State Council, and to break down the main problems in relation to unmanned driving, and to clarify the functions and responsibilities of various departments.

UAVs. Similar to unmanned vehicles, it is suggested that the laws concerning UAVs should also be made in the principle of "amending old provisions and establishing new ones", so as to form a comprehensive and systematic regulation on UAVs. Firstly, strengthen the research on management demands. We should strengthen the research on the demand for UAV applications in transportation field, and strengthen the guidance and direction for the development of unmanned aircrafts from the viewpoint of transportation demand. Secondly, strengthen the research on the legislation concerning 
UAVs. We should strengthen policy and technology reserves so as to better guide and regulate the application and development of UAVs in the transportation sector.

Unmanned Ships. In order to regulate the research, experiment, safety and proper growth of unmanned ships, we should, under mature conditions, draft and implement special regulations on management of experimental navigation of unmanned ships, so that we could take the lead in and regulate unmanned ship technology and industrial development within an appropriate and effective legal framework. Firstly, general laws and regulations, in relation to, for example, ship definition, registration, rights to free navigation and free passage and others, should be improved. Secondly, the laws and regulations on ship safety should be improved. The related conventions, laws and regulations mainly include International Convention for the Safety of Life at Sea, International Regulations for Preventing Collisions at Sea, the Law of the People's Republic of China on Maritime Traffic Safety, the Regulations on the Administration of Inland River Traffic Safety of the People's Republic of China, the Regulations on the Inspection of Ships and Offshore Installations. Thirdly, the laws and regulations on prevention against pollution caused by ships should be improved. It mainly covers the International Convention for the Prevention of Pollution from Ships, the Marine Environmental Protection Law of the People's Republic of China, the Law of the People's Republic of China on Prevention and Control of Water Pollution, and the Law of the People's Republic of China on the Prevention and Control of Atmospheric Pollution. Fourthly, administrative regulations on crew members should be improved. It mainly covers the International Convention on Standards of Training, Certification and Watchkeeping for Seafarers, the International Labour Convention, and the Minimum Safe Manning Rules for Ships. Fifthly, the laws and regulations on maritime rights and responsibilities should be improved. It mainly involves the Maritime Law of the People's Republic of China and other laws and regulations, and covers the legal content of the "captain" responsibility, marine salvage, legal subjects and insurance liabilities in relation to unmanned ships.

In addition, it is required to further revise and perfect the administrative regulations on motor vehicle maintenance and other relevant departmental regulations, to issue the administrative measures for pooling cars as soon as possible, and to ensure the sustainable development of new operational types of the transportation industry, thereby making new contributions to promote China's economic and social development, and effectively solve the major contradictions in the new era.

\section{References}

[1] Mingxun Xu, Wentao Liu and Shuo Xu: "Internet +" and Consummation of Social Legalization: Taking the Transportation Industry as an Example. Journal of University of Science and Technology Beijing (Social Sciences) Vol. 33 No. 3 (2017), pp. 103-110

[2] Xin Rao and Xingyuan Yu: Thoughts on Promoting the Development of New Format of "Internet + Transportation" in China. E-Commerce, Vol. 25 No.13 (2018), pp. 25-27

[3] Yaning Li: Research on the Legal System of UAV Safe Operation under Combined Transportation System. Chinese Laws, Vol. 25 No. 2 (2018), pp. 169-179

[4] Xiaolin Chen: Challenges of Unmanned Vehicles to Current Laws and the Countermeasures. Theory Journal,Vol. 33 No. 1 (2016), pp. 124-131 